\title{
Web-connected weather station based on Arduino
}

\section{Dipankar Haloi ${ }^{1}$ and Papumoni Saikia ${ }^{2}$}

\author{
'ME Student, Jorhat engineering college, \\ Jorhat, Assam, India, \\ ${ }^{2}$ Assistant Professor, Jorhat engineering college, \\ Jorhat, Assam, India,
}

\begin{abstract}
This project presents the development of real time weather monitoring system based on arduino low cost web connected weather station. The system able to display the information of the weather parameter via a website using to a $\mathrm{Wi}-\mathrm{Fi}$ module. The measurement parameter includes temperature, light intensity, humidity, rain drop, wind speed, wind direction and barometric pressure. The user can monitor the weather continuously though the JEC weather station website and can leverage the information to their needs. Through the development of this weather monitoring system the cost of the service can be reduced.
\end{abstract}

Keywords: Arduino, weather station, portable, weather monitoring, website.

\section{Introduction}

A group of persons in the Jorhat Engineering College build a web-connected weather station. This can be done with a small investment in time and money. The weather station is build and installs it in some suitable location in the JEC campus to get accurate measurements; installation has to obey many guidelines such as so many $\mathrm{ft}$. above the ground etc. The design and construction of enclosures for the electronics will require some trial and error, since it has to protect them from the environment without hampering accurate measurement of the environment. Not a trivial design problem. A suite of web applications should be written to continuously pull the data and store in a relational database as well as display it on some website, preferably on the JEC website. The wind speed and direction meter can be constructed locally in the JEC campus.

\section{Working Principle}

In this weather station, the various sensor like as dht11, LDR, rain drop, barometric pressure sensor, wind speed and direction sensor are connected to different pins in the arduino board. All sensors are connected to the microcontroller each of them taking $5 \mathrm{~V}$ input from arduino except pressure sensor requiring $3.3 \mathrm{~V}$. We've used dht 11 sensor to get the value of temperature and humidity of the campus. It is connected to analog pin A0 on the arduino board for input signal. A rain drop sensor is also connected analog pin A2 on arduino board to take input signals from the sensor. It is a device for rain detection. This tool contains a rain board which detects the rain and gives status whether there is any rain or presence of the rain in the campus. One more sensor attached which is LDR sensor from analog pin A0 on the arduino to take input signals from the sensor. It is used to measure the value of fluctuating resistance when it engages with light. If the light is deceases then it gives lesser value of lower light intensity. BMP180 pressure sensor is also attached to arduino analog pin A4 from SDA pin of the sensor and analog pin A5 from SCL pin of the sensor. It is used to measure the absolute pressure of the air around them. Pressure is inversely proportional to altitude so could be used to measure the altitude too. Two more sensors attached which are wind speed sensor and wind direction sensor from analog pin A2 and digital pin 2, 3 on arduino to take input signals from the sensor. In this project, The data are collected from sensors using by arduino. The sensors data send from arduino to mysql database by using python. when data store in the data base, it goes >= 1000 and then the data are delete using FIFO system. By using php the resultant value insert to the website and LCD from mysql database every 9 or $12 \mathrm{sec}$. After completed the connection 
of arduino and various sensors which are placed in the JEC campus and code uploading procedure, the sensors data will be display in the LCD and the serial monitored of the PC. We have used a Wi-Fi module to connect it to the internet connection provider. Its job is to transmit the data to a website linked to it and visualize the data over there for every 9 or 12 seconds.

\section{Hardware Structure}

\section{A. BLOCK DIAGRAM}

The block diagram of the system is shown in figure1. The $5 \mathrm{~V}$ power source supplies to the microcontroller, all the six sensors, the LCD and the serial port. The six sensors are connected to six different ADCs on arduino board. The sensor output of the system are displaced on the LCD and sent to the serial port that can be read by a personal computer.

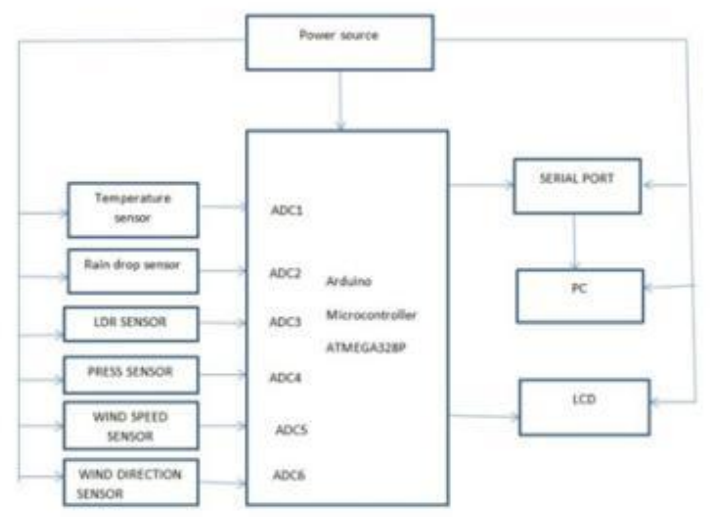

Figure 1: Block diagram of the system

\section{B. CIRCUIT DIAGRAM}

Fig 2 shows the circuit diagram of the system and a details description of the circuit diagram to implement the system is given below.

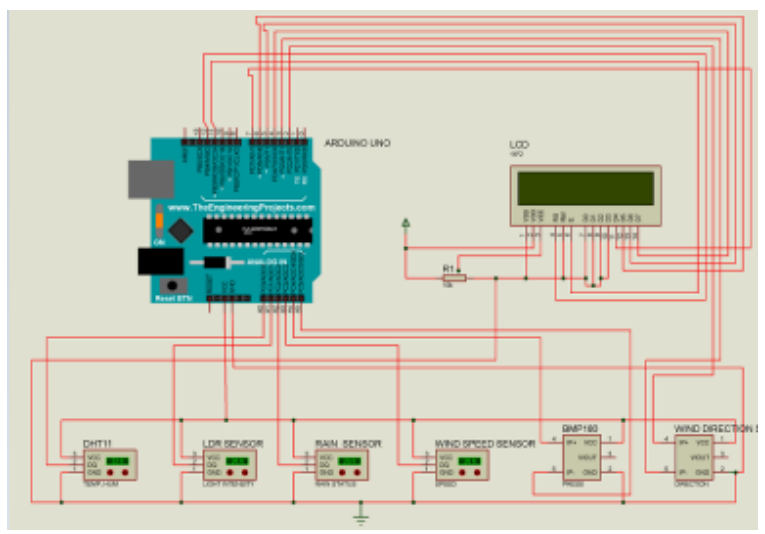

Figure 2: Circuit diagram of the system

\section{Circuit Explanation}

\section{A. Arduino}

In this project, arduino UNO board is used consisting of ATMEGA328P microcontroller which provides a $5 \mathrm{~V}$ and $3.3 \mathrm{~V}$ output voltage. It is cheap and feasible. the board can be powered by using USB connection or using a external power supply.in this arduino board, the codes are uploaded using arduino IDE software. It consists of 14 digital pins and 6 analog pins. It takes input voltage in between $7-12 \mathrm{~V}$.

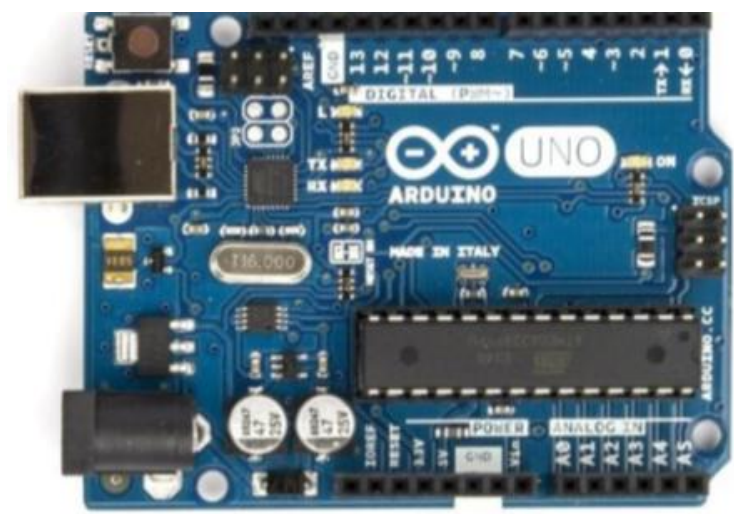

Figure 3: Arduino board

\section{B. DHT11}

This sensor is used for measuring humidity and temperature of the surrounding. The operating voltage of this sensor is $3.5 \mathrm{v}$ to $5.5 \mathrm{v}$. The temperature range of the sensor is $0^{\circ} \mathrm{C}$ to $50^{\circ} \mathrm{C}$ and the humidity range is $20 \%$ to $90 \%$.

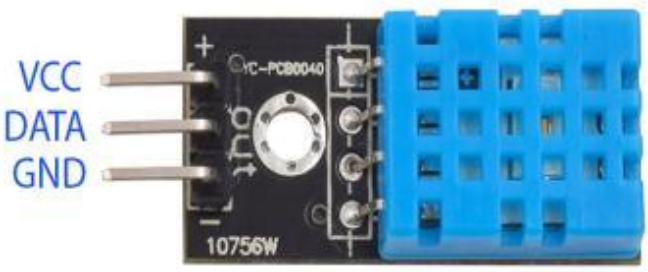

Figure 4: dht11 sensor

\section{Raindrop sensor module}

It is a tool for rain detection. The module contains a rain board which detect rain drop whether there is any rain or presence of the rain in the campus. It gives only analog output. 

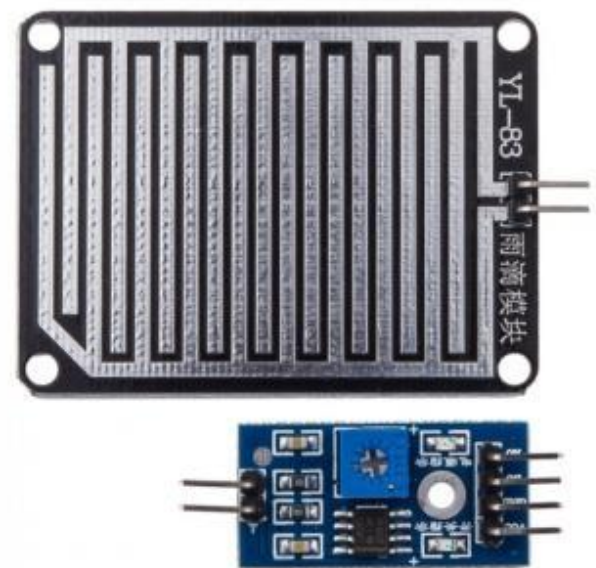

Figure 5: Rain drop sensor

\section{BMP180 sensor}

It is used to measure the absolute pressure of the air around them. This pressure varies with both the weather or altitude. It contains 4 pins like as sda, scl, gnd and vin.

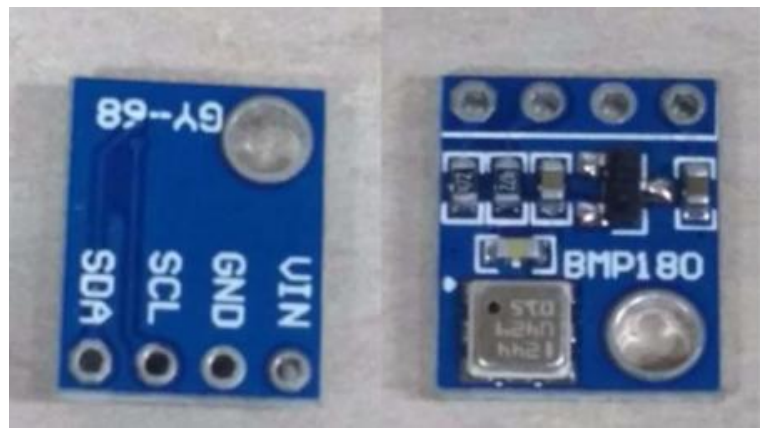

Figure 6: Barometric pressure sensor

\section{E. LDR Sensor module}

In the LDR sensor module is used to detect the ambient brightness and light intensity. If the light is decreases then decreases the value of the lower light intensity.

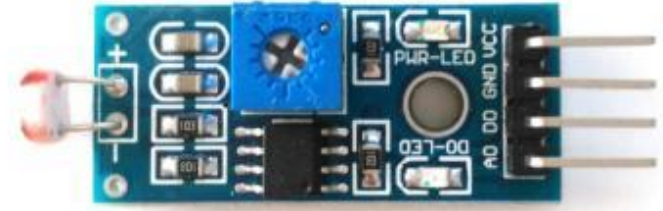

Figure 7: LDR sensor

\section{F. Wind Speed meter}

The wind speed meter can be constructed locally in the JEC campus. The wind speed meter consists of five parts:

a) Hall effect sensor: A Hall effect sensor is a device that is used to measure the magnitude of a magnetic field. Its output voltage is directly proportional to the magnetic field strength through it.

b) Encoder.

c) Rotor: This rotor can be easily spined which makes the wind speed sensor able to work at a low wind speed.

d) Plastic sticks and bowls: We are used for the frame of the fan blades.

e) Base: It is a base to hold the rotor and keeps the whole wind speed sensor's center of gravity low.

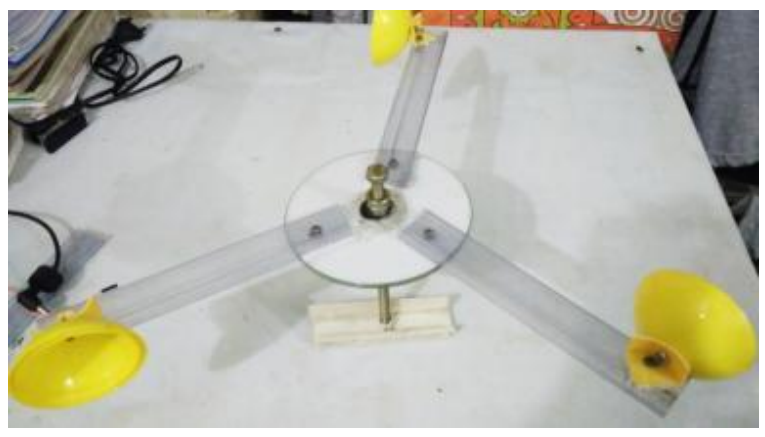

Figure 8: Wind speed meter

\section{G. Wind Direction Sensor}

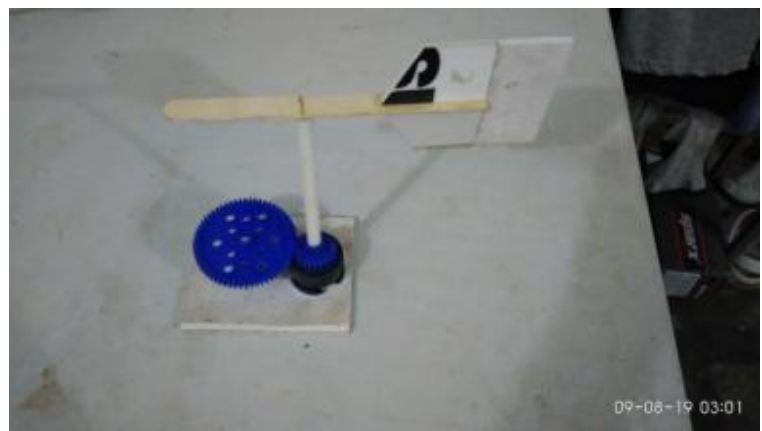

Figure 9: Wind direction meter. 
The wind direction sensor is a I-turn continuous potentiometer. A I-turn continuous potentiometer means the resistance of the potentiometer does not accumulate when the axis turns cycle by cycle. So every position of the axis has a fixed value of resistance. Supplied with $5 \mathrm{~V}$ power resource, the microcontroller can read the voltage of each direction through analog-to-digital converter (ADC).

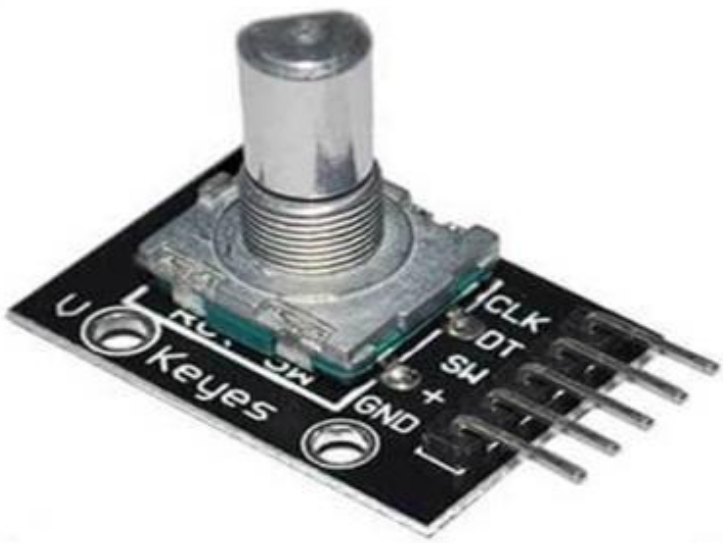

Figure 10: Wind direction sensor

\section{H. Liquid Crystal Display (LCD)}

The microcontroller output is directly send to the input of the LCD so that the status of slot and count calculated by the microcontroller can be monitored or display on the LCD. Basically LCD is a seven segment display and we used $16 \times 2$ alphanumeric ie capable of displaying character or rather character string.

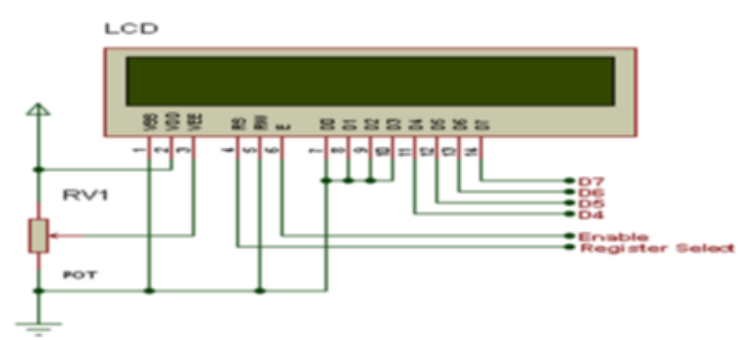

Figure 11: LCD

\section{Software System Structure}

The software system design includes two parts, the data input from hardware sensors and the data output to the website connected to a computer and LCD.

\section{A. Software used}

1. Arduino Software IDE
2. PROTEUS ISIS
3. Python
4. Html
5. Php
6. MySQL
7. Ngrok

\section{B. Flowchart}

The microcontroller reads the analog to digital converter data from the various sensors. The weather station will capture the wind speed signal, wind direction signal, LDR signal, Rain drop signal, barometric pressure signal and temperature signal through the A/D converter. The microcontroller is processing data that it receives from the analog to digital. The weather station will display this data on the LCD and sent data to a computer through serial port.

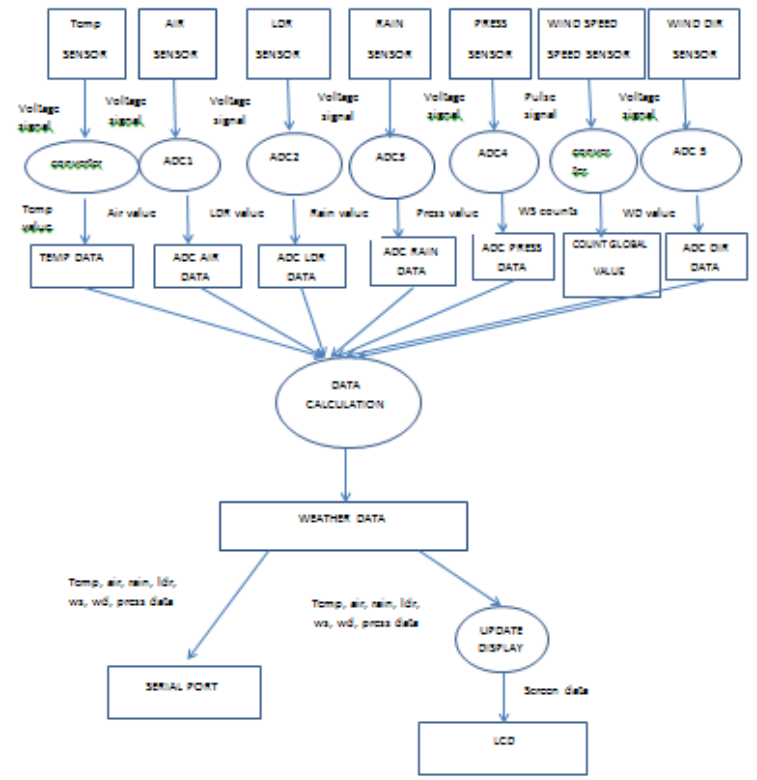

Figure 12: Flowchart of the system

\section{Results And Discussion}

A. LCD display

In LCD, display the value of various sensors connected to arduino and the screen shoot of LCD is given bellow:

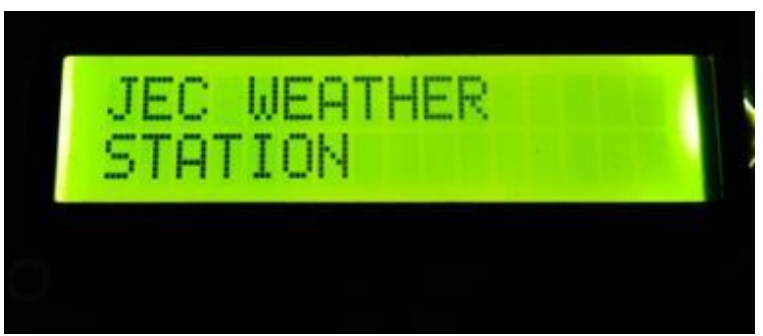




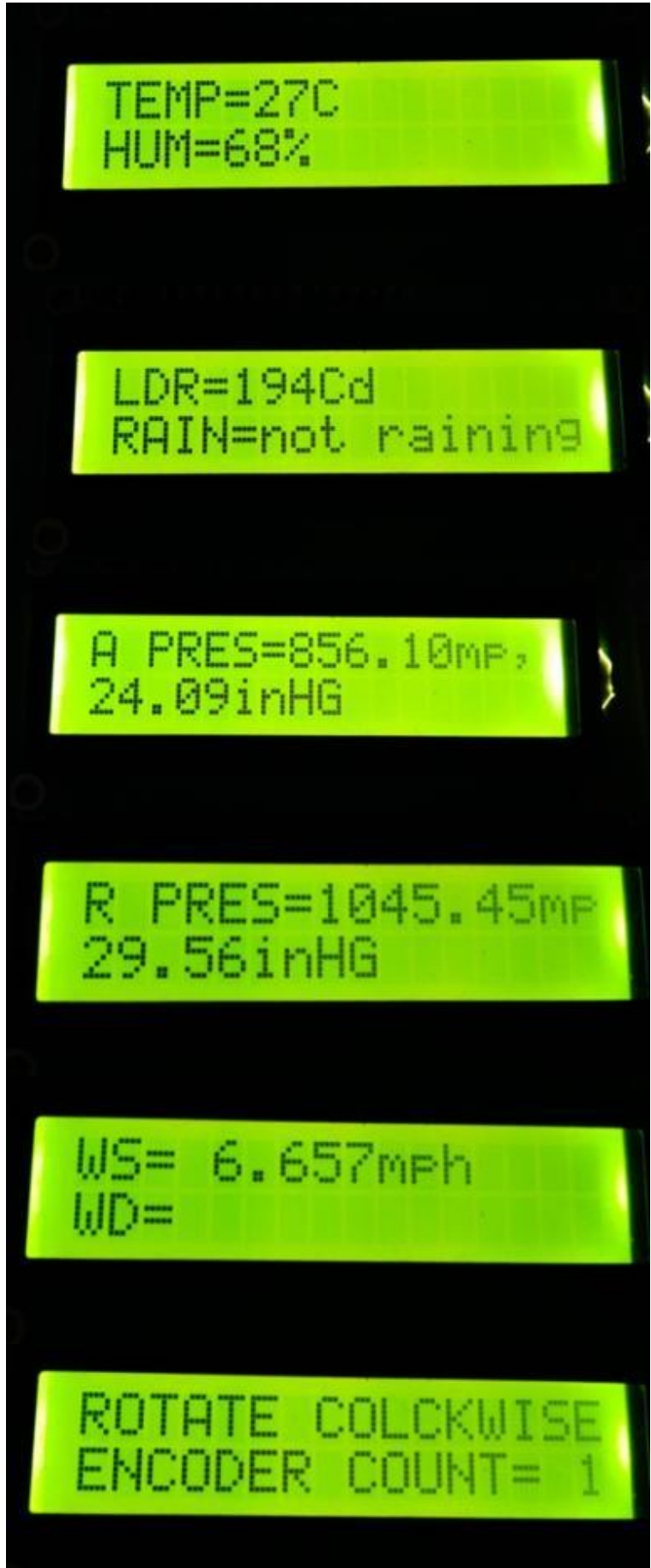

Figure13: LCD display

B. website of the system

In our JEC weather station website display the value of various sensors connected to arduino and the screen shoot of JEC weather station website is given bellow:

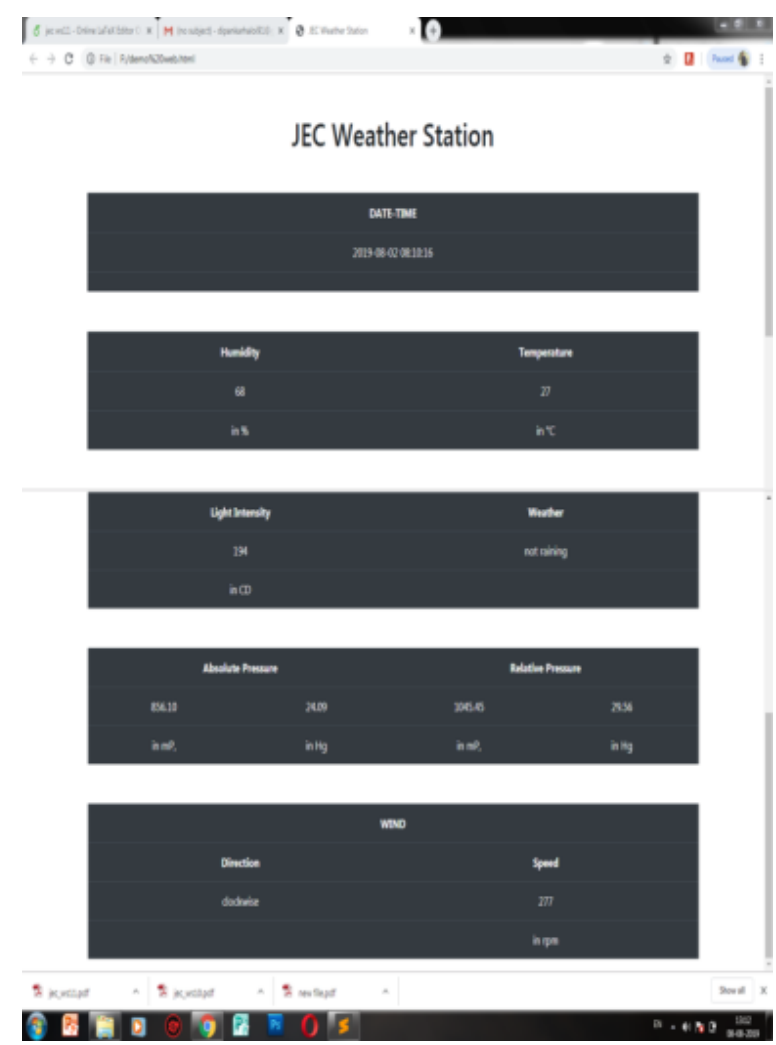

Figure14: Screenshot of the website

\section{Database of the system}

In this project, the various sensors value are stored in the data base of JEC weather station.

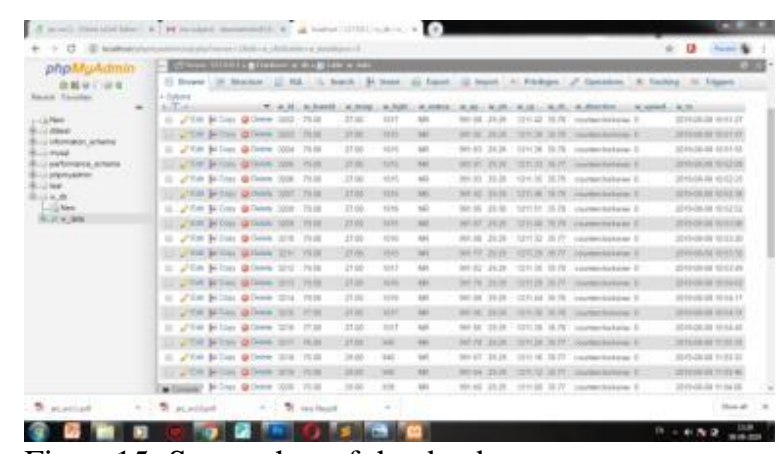

Figure15: Screenshot of the database

\section{Experimental Setup}

The experimental setup of the project "Design a low cost web connected weather station in JEC campus" is shown below: 


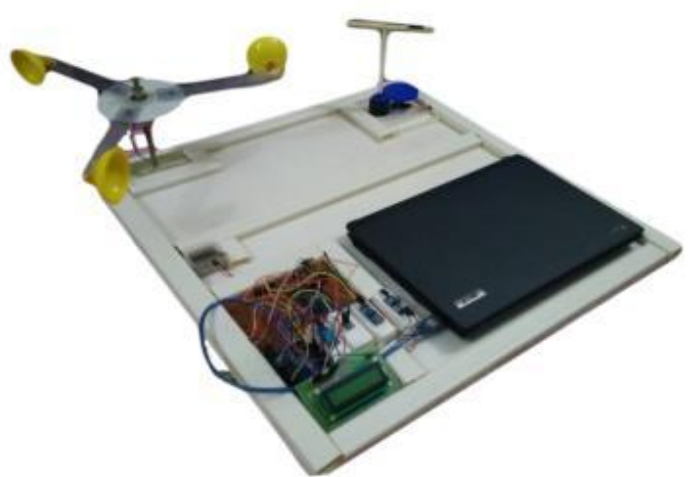

Figure15: Experimental Setup of the system

\section{Future Scope}

Our further work on this station will be oriented to add more sensors and devices in order to improve whole weather station and expand the range of its use. For future work, the author will focus on the data storing and analysis. The data obtained from the web connected weather station will be stored on a personal computer and according to the history more useful information can be predicted.

\section{Conclusion}

The main objective are to find an affordable and functional solution for real time monitoring climate and weather data in micro locations(JEC campus) using the sensors for temperature, light intensity, humidity, rain drop, barometric pressure, wind speed and wind direction in combination with arduino. We developed a prototype of the weather station which data are transferred via Wi-Fi to a website and presented with the application designed for this project.

\section{Acknowledgment}

I take this opportunity of thanking my dissertation guide Mr. Papumoni Saikia, Assistant Professor, Department of Electrical Engineering, Jorhat Engineering College, Assam for his indispensable guidance, generous help, perpetual encouragement, constant attention offered throughout in preparation of this dissertation. I am grateful for the support and guidance provided by him.

\section{References}

[1] R. K. Kodali, and S. Mandal, "IoT Based Weather Station”, 2016 International Conference on Control, Instrumentation, Communication and Computational Technologies (ICCICCT), 2016 IEEE.

[2] A. Munandar, H. Fakhrurroja, M. I. Rizqyawan, R. P. Pratama, J. W. Wibowo and A. I. A.Fakhry, "Design of Real-time Weather Monitoring System Based on Mobile Application using Automatic Weather Station", 2nd International Conference on Automation, Cognitive
Science, Optics, Micro Electro-Mechanical System, and Information Technology (ICACOMIT), october23,2017.

[3] J. Christopher, B. Lopez and H. M. Villaruz, "Low-Cost Weather Monitoring System with Online Logging and Data Visualization" 8th IEEE International Conference Humanoid, Nanotechnology, Information Technology, 912 December 2015

[4] A. Shaout. Y. Li, M. Zhou and S. Awad, "Low Cost Embedded Weather Station with Intelligent System” 2014 IEEE.

[5] S. Trifun, R. Milutin, "One Approach to Weather Station Design Based on Raspberry Pi Platform", 23rd Telecommunications forum TELFOR 2015 IEEE

[6] A. Katyal, R. Yadav and M. Pandey, "Wireless Arduino Based Weather Station" International Journal of Advanced Research in Computer and Communication Engineering. Vol. 5, Issue 4, April 2016.

[7] M. S. Ali, A. O. Akode, S. D. Awadalkareem and F. M. Ahmed, "A Design of a Remote Weather Factors Monitoring System", 2017 International Conference on Communication, Control, Computing and Electronics Engineering (ICCCCEE), Khartoum, Sudan.

[8] B.S. Rao, K. S. Rao and N. Ome, "Internet of Things (IOT) Based Weather Monitoring system", International Journal of Advanced Research in Computer and Communication Engineering, Vol. 5, Issue 9, September 2016

[9] M. Yamanouchi, H. Ochiai, Y. K. Reddy, H. Esaki and H. Sunahara," Case study of constructing weather monitoring system in difficult environment", 2014 IEEE.

[10] M. Masinde, A. Bagula and M. Nzioka "SenseWeather: Sensor-Based Weather Monitoring System for Kenya", IIMC International Information Management Corporation, 2013. 